\title{
PERSONA AND DEFENCE MECHANISMS
}

\author{
WAYNE C. HUDSON, New York
}

\section{INTRODUCTION}

A REVIFW of the literature concerning the persona indicates that a great deal remains to be known concerning this particular component of the psyche. Apart from a reiteration of Jung's statement on the persona, few theorists or clinicians, with the exception of Jolande Jacobi, in her important work Die Seelenmaske, have commented on the various manifestations of the persona (JACOBI 9). In this paper $I$ intend to cover briefly some of the major areas of consideration which I feel need further development in order to enhance the understanding of the development of the persona and its relation to psychopathology.

Jung describes the persona as 'a compromise between individual and society as to what a man should appear to be' (JUNG I2, p. I 56). The persona acts, on the one hand, to make definite impressions upon others and, on the other, to conceal the true nature of the individual. It is a social rôle or mask which acts as a mediator between the inner world and the social world, and which constitutes the compromise between the individual and society.

While Jung did not specifically trace the developmental influences on the persona, he did imply that its moulding is largely social when he stated that its making is often more attributable to others than to the person himself (JUNG ro), or when he said, "We might define this false self as the persona; that general idea of ourselves which we have built up from experiencing our effect upon the world around us and its effects upon us' (JUNG II, P. 2I8).

Jolande Jacobi's major work, Die Seelenmaske, concerns the manifestations of the persona and of the inflated persona, but primarily with reference to the adult. Her book examines the persona in the social context with emphasis on the persona's link between the social milieu and the archetypes. She also emphasises neurotic manifestations created by the persona's potential isolation of the self from the environment leading to feelings of emptiness and unreality (JACOBI 9).

Whitmont states that the pseudo-ego stereotypy of persona identification can stop the development of, or atrophy, the ego. In defining the persona, Whitmont emphasises not only the cultural function of the persona, but the effects which early parental demands have on its development (WHITMONT 20). 


\section{DEVELOPMENTAL ASPECTS}

Many contributions to the understanding of the development and relative importance of the persona have come from theorists who have examined the development of the schizoid personality. The duality of the conscious ego and the conscious persona is a phenomenon with its roots in the schizoid position, and the concept of the persona is closely associated with the psychoanalytic concept of the false self (WINNICOTT 2I).

Melanie Klein's early work with object relations theory was a forerunner of much of the work concerning schizoid mechanisms and the development of the false self (GuNTRP 6). In her work on the paranoid-schizoid position she commented on how unassimilated idealised objects could be introjected into the psyche, causing the ego to have less value of its own. These unassimilated idealised objects thus may form the foundation of autonomous competing structures (KIEIN I3).

Fairbaim expands on this type of conceptualisation but with a theory which is more interpersonal in nature. He emphasises the importance of the mother-child relationship in the development of schizoid mechanisms. $\mathrm{He}$ stresses that the relative importance attributed to schizoid mechanisms, and whether or not they will be used as a psychic defence mechanism in adult life, is largely due to the nature of the mother-child relationship during the first few months of a life (FArRBAIRN 3). M. Esther Harding has analogously emphasised the importance of that relationship in the development of the persona. She views the persona as the mark of good and adapted behaviour which is communicated to the child by the mother (Harding 7).

Lichenstein believes that the mother imprints an identity theme on the child (IICHENSTEnN IS). An ideal image, which is based on that of the good desirable child, is conveyed by theloved object to the child (SANDLER, HOLDER, MEERS I9), but the child's ability to integrate such an image into his being seems to depend on the degree to which schizoid mechanisms dominate the psychic functioning.

Winnicott attributes false self development to adaptation failures in the early maternal environment (WINNCOTT 2I). The environment seduces and frightens the infant into the development of the false self. Winnicott sees the mother's ability to meet the child's omnipotence as giving impetus to the true self, while blocking in symbolic communication between the mother and the child fosters frustrations and encourages the emergence of a false self (WINNICOTI 22).

Ritvo and Solnit also suggest that the child uses imitation to satisfy the mother with a good performance in order to overcome blockage in the mother-child relationship (Rrrvo, SoLNI 18). This idea of development which is reactive to problems in the environment is not unlike Fordham's developmental scheme whereby the primary self is deintegrated as a result 
of the interaction with the environment. The persona thus develops as a series of compromises between the primary self and the environment during the stage of the schizoid position. If this takes place within a normal range of anxiety we may call the persona which develops an acceptable compromise, as a mediator between inner and outer worlds. If, however, the infant experiences high anxiety during that stage owing to failures of the maternal environment, then more and more compromise is made to the outer world at the expense of the primary self. This exaggerated persona, which is clearly schizoid in its separation of good and bad internalised objects, comes to be used defensively.

Fairbairn suggests that the false self, or the adopted rôle, is initially adopted to minimise conflict between the mother and child, and is then used defensively in adult life as a façade to the inner ego in order to avoid genuine emotional contact or genuine giving, both of which seem threatening to the psychic stability (FaIrbarre 3 ).

This false self development, which is initially adaptive and maximises gratifications, may become maladaptive by over-emphasis. If the early environment presents many adaptation failures, then deceptive strength will be given to the emerging false self, which then becomes the basis for later social relationships to the exclusion of the real self.

It would seem then that the persona is given its impetus and relative importance mainly by the initial mother-child relationship. This view then presents a multi-factored description of the persona whose basic nature is collective; it develops into specific rôles and modes of action through interaction with the social milieu, and its importance, and the degree to which it will be manifested in any particular person, are attributable to the underlying importance of the schizoid mechanisms which are derived from the early maternal relationship.

\section{PERSONA IDENTIFICATION}

The next area of consideration concerns those circumstances in adult life which lead to over-emphasis of, or identity with, the persona.

Components and primitive defence mechanisms from the schizoid position seem to be present in all types of personalities, but with varying degrees of importance. For that reason regressive trends toward temporary persona identification are typical human experiences. In those people, however, in whom schizoid mechanisms have primacy, the process of persona identification may be sustained for long periods of time and may be accompanied by intense disorganisation within the psyche.

All neurotic trends seem to manifest themselves in some type of social maladaptation, and from this it would seem that many patients see that social maladaptation as the cause rather than the effect of this pathological trend and resulting anxiety. As a result they may begin to conform blindly to outer 
demands, becoming totally identified with their social aspect as a defence against unsolved inner conflicts (GROOT 5). The child develops the false self to minimise frustration and to maximise gratification from the mother, so that when the adult is in an anxiety situation there is an unconscious wish to restore contact with the protective gratifying mother which, in turn, increases the identification with the false self or persona.

The major problem presented here is that if this persona identification is used as the major defence against anxiety, then rather than being adaptive it will lead to more anxiety and more severe pathology. Reich points out that a narcissistic imbalance, such as persona over-cathexis, leads to emptiness, lack of genuineness, and severe depersonalisation (REICH I6). This compulsive and inflexible identification leads to a starvation of the ego, blocks the development of inner psychic functions and leads to what Jung describes as soullessness.

The pathological aspects of this persona identification are similar to what Erikson described as pathological ego identity, when the person becomes preoccupied with how he appears to be in the eyes of others compared to what he is (ERIKSON 2). Fromm also describes how acting as a response to other's wishes leads to a pathological identity state, which jeopardises the genuine feelings of the self (FrOmm 4).

This pathological persona identification has been observed in a more extreme form in psychotic personalities. Arieti found that the pre-psychotic personality was one in which the identity is not in the core of being, but is a reflection of how the person feels others deal with him (ARIETI I). This view of pathologic identification, which can be equated with the persona, is also held by Laing. The schizoid personality which Laing describes, experiences itself as a response to other people. He contends that in the schizoid personality the false self becomes more and more compliant to the social reality (LAING I4).

The neurotic is able to use persona identification in varying degrees as a temporary defence mechanism without losing ego identity. It is possible for the neurotic to increase persona identification and, at the same time, maintain ego identity. In the schizophrenic, however, persona identification is a more direct manifestation of the schizoid mechanisms which dominate the personality. Unlike the neurotic, the schizophrenic must either identify completely with the persona or not at all, since the primitive defence mechanisms of splitting and denial keep all other psychic structures, such as the shadow-associated ego components, separate from the persona.

Prior to an acute episode it is not unusual for a schizophrenic to have a period of increased persona identification, corresponding with the increased activity of the primitive defence mechanisms of splitting, denial, and projective identification. The greater the distance between the good and bad internalised objects due to splitting and denial, the more exaggerated the persona. When the defence mechanisms are no longer able to hold, a 
regression to an acute psychotic episode occurs. Then, typically, the persona recedes and the shadow-associated ego components emerge, at least temporarily.

\section{CLINICAL STUDY (I)}

Fred was a 26-year-old college student. Fred's father had died when Fred was ten and his mother, now in her sixties, lived some I,000 miles away. Fred had an older sister who also lived some distance away. Fred's personality structure might be described as borderline; there had been an acute psychotic episode at the age of eighteen, requiring two weeks in hospital and another acute episode at the age of twenty-six requiring six weeks in hospital.

Fred had attended and dropped out of several colleges before enrolling in a religiously affiliated college in order to study to become a missionary. He was in his third year of study and living on the school campus. Fred's outward personality was one of benevolence, reverence, propriety and dedication to the principles of the church. He began to experience frightening dreams in which he would rape and kill the cleaning woman at the school and attack and mutilate his room-mates. These dreams became more and more disturbing to him, but he was afraid to go to the school counsellor for fear of being 'found out'. The intrusion into consciousness of the shadow elements compelled him to identify further with the persona caricature of his espoused virtues. The dreams, however, continued and the prevailing ego structures began to break down, allowing the dream motifs to be acted out. He began to be threatening and verbally obscene toward the people at the college. This was followed by extreme anxiety regarding being 'found out' by God, which in turn led to an acute psychotic episode during which he became more abusive and aggressive. It was at this point that he was put into hospital.

Shortly after this Fred's persona re-emerged. He denied his previous shadow-related behaviour and began to conduct himself on the ward as a very proper devout person. Although he spoke of his mother in highly idealised terms, he asked that she should not be notified of his hospitalisation for fear of his being 'found out'.

It was only after an intense transference had developed with the therapist that Fred could discuss any of the shadow-associated material, and even then only after prolonged sessions. He would typically begin a session in a highly resistant state, and it was only after he was relaxed that the shadow material began to emerge. When it did there would be a flood of imagery and affect followed by a re-emergence of the persona with almost no carryover from one state to the other. During periods of anxiety, when the splitting mechanisms were active, he would deny having ever talked about any of the shadow material. 
PERSONA AS RESISTANCE

The final area of consideration is the relationship of the persona to the question of resistance to psychotherapy.

Jung commented on how the dissolution of the persona may leave the patient disoriented as he becomes increasingly aware of unconscious material (JUNG I2). This is supported by Winnicott's statement that when the patient gives up the false self he becomes very dependent on the analyst (WINNIcorr 22). This phenomenon can be explained by the fact that the persona has been cathected as the psychotic centre, and when it is de-emphasised there is a transitional state before the psyche is oriented on an ego-self basis. Another factor is that the de-emphasis of the persona deprives the unconscious of a means with which it has previously attempted to restore the gratifying, protective mother. During this phase the patient may substitute the therapist for the gratifying protective mother and enter into an introjective dependent relationship with the therapist. The introjected 'good object' therapist may act as a stabilising force in the psyche and help in the constellation of the egoself as the centre of the personality. That, however, refers only to the inner conflict which arises from the dissolution of the persona and ignores the outer conflict which is associated with the secondary gains which the persona has brought in the social milieu.

From the outset of psychotherapy there will be a resistance to change in the persona, because through identification it has become the basis for the patient's interpersonal interactions. The relationships which the patient has formed, no matter how superficial, are his only relationships and to modify the persona is to threaten his entire interpersonal field. In addition, the persona, which is perhaps long-standing in its present exaggerated form, may dominate the patient's entire mode of behaviour: it has become more than a rôle, it is the person's characteristic pattern of behaviour. Winnicott notes that the inflated false self which is often associated with the intellect may carry with it considerable social success (WINNICOTT 22). Such a person's attempt to maintain the outward-directed aspects of the personality, while denying the inward, no matter how neurotic and painful that artificial behaviour may be, is referred to by Horney as neurotic pride, and it acts as a resistance from the outset of psychotherapy (HORNEY 8). A double-bind situation is thus created in which, if the person continues with the inflated persona he suffers from the anxiety of an isolated dissociated self, while the initial movement away from the persona confronts him with the anxiety associated with changing his interpersonal environment and his outer reality.

The defensive characterological position, which is encountered with persona identification, is not unlike Reich's character armour. Reich described character armour as the sum total of those influences of the outer 
world on the instinctual life which, by reason of their similarity, form a historical unit (REICH I7).

The foregoing suggests that early in therapy a character analysis of the persona is advisable and necessary. It would enable the patient to increase his insight into the way in which his rôle has influenced his various modes of relating in the context of character formation, and would also heighten his awareness of his individual personality and as to which of his social interactions are occurring in relation to his persona. The analysis of the persona tends to decrease resistance to psychotherapy and change results once the patient is able to define the boundaries between ego and persona and to reestablish some degree of inner-directedness. Even with the initial persona analysis one cannot underestimate the potency of the secondary gains from the persona, or the resistance which will be encountered if the persona modification has dramatic effects on the social milieu.

\section{CLINICAI STUDY (2)}

A pronounced example of the conflict between the forces which work towards changing the persona and those that aim at maintaining the social milieu was given in the case of the patient previously described. For Fred to make alterations in his persona, or in the degree to which he identified with it, threatened his career goals as a missionary, his current standing in college and his circle of friends who were, for the most part, other missionary students whose relationships with Fred were largely based on his persona. Every time Fred made an attempt to alter the persona there was an increase in anxiety, not only from the unconscious process involved, but also because changes in Fred's persona would cause the people in the environment to relate to him in a different manner. This was compounded in Fred's case because he used his tie with the church as a supportive substitute for his family. Therefore as anxiety increased, owing to psychic change, the people he would have normally relied on for support were simultaneously becoming more estranged.

Another patient had developed the persona of a high-achievement intellectual. The patient's mother had always put great emphasis on tangible accomplishment as a means of gaining her love and attention.

The patient developed the persona in line with those maternally demanded goals at the expense of other personality components, especially emotionality. Although very unhappy in his adult rôle as president of a publishing firm, the patient did, however, fear that any change in the persona would threaten his position as corporate president. While he seemed somewhat willing to risk his title, he was unwilling to risk his very high salary. In addition, his social standing and circle of friends were largely based on his degree of persona identification. 


\section{SUMMARY}

I have tried to present material in several major areas to enhance the understanding of the persona. The relationship between the early maternal environment and the schizoid position has been correlated with the foundation of the persona and the determination of its later importance as a defence mechanism. The adult circumstances under which persona identification occurs were examined. Finally, the persona was considered as a source of resistance to psychotherapy owing to the secondary gains which the persona brings from the social environment.

\section{REFERENCES}

I. AREETI, S. (1967). The intrapsychic self. New York, Basic Books.

2. ERIKSON, E. H. (I968). Identity, youth and crisis. New York, Norton.

3. FambanRn, R. D. (I952). Psychoanalytic studies of the personality. London, Tavistock.

4. Fromm, E. (I94I). Escape from freedom. New York, Holt, Rinehart and Winston.

5. Groor, J. Lampl-de, (1966). 'Some thoughts on adaptation and conformism', in Psychoanalysis: a general psychology. New York, International Universities Press.

6. GuNTRIP, H. (I97I). Psychoanalytic theory, therapy and the self. London, Hogarth.

7. Harding, M. E. (1965). The I and the not I. Princeton University Press.

8. HoRNEY, K. (I950). Neurosis and human growth. New York, Norton.

9. JACOBI, J. (1967). Die Seelenmaske. Olten, Walter Verlag (trans. E. Begg as Masks of the soul, London, Darton, Longman and Todd, I976).

Io. Jung, C. G. (I917). 'On the psychology of the unconscious', Coll. wks. 7 .

II. - (1921). Psychological types. Coll. wks., 6.

I2. - (1928). 'The relations between the ego and the unconscious', Coll. wks., 7 .

I3. KIEIN, M. (I9S2). Developments in psychoanalysis. London, Hogarth.

I4. LAING, R. (I960). The divided self. London, Tavistock.

I5. Lichenstems, H. (I96i). 'Identity and sexuality', J. Amer. Psychoanal. Assn., 9, pp. I79-260.

16. Rerch, A. (I960). 'Pathological forms of self-esteem regulation', in The psychoanalytic study of the child, 15. New York, International Universities Press. London, Hogarth.

17. REICH, W. (1945). Character analysis. New York, Orgone Institute Press. 
I8. RrTvo, S., SoLnTr, A. J. (1958). 'Influences of early mother-child interaction on identification processes', in The psychoanalytic study of the child, 13. New York, International Universities Press. London, Hogarth.

19. SANDIER J., Holder, A., Meers, D. (1963). 'The ego ideal and the ideal self', in The psychoanalytic study of the child, 18. New York, International Universities Press. London, Hogarth.

20. Whimmont, E. (I969). The symbolic quest. New York, Putnams' Sons.

2r. WInNicotr, D. W. (1958). Collected papers. London, Tavistock.

22. (1965). The maturational process and the facilitating environment. London, Hogarth. 
Copyright of Journal of Analytical Psychology is the property of Blackwell Publishing Limited and its content may not be copied or emailed to multiple sites or posted to a listserv without the copyright holder's express written permission. However, users may print, download, or email articles for individual use. 